\title{
Factors Influencing Subspecialty Training and Career Choices: A National Survey of Physical and Rehabilitation Medicine Residents
}

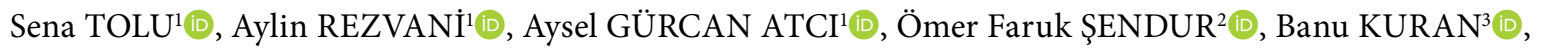

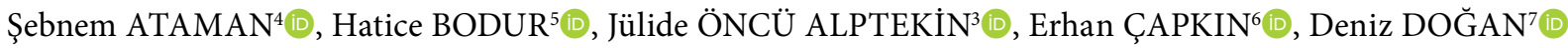 \\ ${ }^{1}$ Department of Physical Medicine and Rehabilitation, Medical Faculty of Bezmialem Vakıf University, İstanbul, Turkey \\ ${ }^{2}$ Department of Physical Medicine and Rehabilitation, Medical Faculty of Adnan Menderes University, Aydin, Turkey \\ ${ }^{3}$ Department of Physical Medicine and Rehabilitation, University of Health Sciences Şişli Hamidiye Etfal Training and Research Hospital, İstanbul, Turkey \\ ${ }^{4}$ Department of Physical Medicine and Rehabilitation, Division of Rheumatology, Medical Faculty of Ankara University, Ankara, Turkey \\ ${ }^{5}$ Department of Physical Medicine and Rehabilitation, University of Health Sciences Ankara Numune Training and Research Hospital, Ankara, Turkey \\ ${ }^{6}$ Department of Physical Medicine and Rehabilitation, Medical Faculty of Karadeniz Technical University, Trabzon, Turkey \\ ${ }^{7}$ Department of Physical Medicine and Rehabilitation, University of Health Sciences Gaziosmanpaşa Taksim Training and Research Hospital, İstanbul, Turkey
}

\begin{abstract}
Objectives: This study aims to determine the preferences of physical and rehabilitation medicine (PRM) residents in Turkey for future career choices, subspecialty training plans, and practice location and to identify the factors that influence those preferences.

Materials and methods: Using a cross-sectional study design, a survey was sent to all PRM residents enrolled in the Turkish Society of Physical Medicine and Rehabilitation and the Turkish League Against Rheumatism $(n=500)$. A total of 181 residents (36\%) $(74$ males, 107 females; mean age 28.8 years; range 24 to 40 years) responded to the survey. Data were collected about demographic profile of respondents and PRM clinics, respondents' experiences in rheumatology education and injection skills, preferences for fellowship training, and future practice location.

Results: Thirty-five percent of residents intended to pursue fellowship training. Rheumatology was more preferred than algology. Male sex was positively associated with the decision to pursue fellowship training and also having an algology division in the PRM department was positively associated with planning to pursue algology fellowship training. For those planning to pursue fellowship training, the most influential factors were prestige, interest in an academic career and the possibility of performing compulsory service in a better location. Thirty-four percent of residents preferred to work in university hospitals after residency while $57 \%$ of residents who planned to pursue fellowship training preferred to practice at university hospitals after their fellowship. Thus, an academically oriented career was the most desirable career choice.

Conclusion: One-third of residents training in Turkey chose to pursue fellowship training and work in university hospitals. Performing compulsory service was the top factor affecting the decisions of both undecided and reluctant residents; thus, career plans of PRM residents in Turkey are not based solely on personal and professional desires, but require consideration of compulsory service.

Keywords: Career planning; compulsory service; physical and rehabilitation medicine resident; subspecialty training
\end{abstract}

Specialists of physical and rehabilitation medicine (PRM) treat a wide range of patients, from pediatric to geriatric ages. The specialty of PRM is approximately 70 years old and interested in a wide variety of musculoskeletal and neurologic problems. In our country, specialists of PRM also deal intensively with the diagnosis, treatment, and rehabilitation of rheumatic diseases. The main reason behind this practice is that such education and skills occupy a highly important place in the core syllabus of the specialty of PRM. ${ }^{1}$ Toward the end of residency

Received: November 20, 2017 Accepted: February 28, 2018 Published online: May 29, 2018

Correspondence: Sena Tolu, MD. Bezmialem Vakıf Üniversitesi Tıp Fakültesi, Fiziksel Tıp ve Rehabilitasyon Anabilim Dalı, 34093 Fatih, İstanbul, Turkey. Tel: +90 505 - 4424722 e-mail: dr.sena2005@gmail.com 
training, specialists of PRM have to make certain decisions such as in the area of interest (academic career, subspecialty interest) and practice location (university, community, private healthcare) for their career. These decisions are influenced by many factors specific to each individual, discipline, and country. According to pediatric residents from Canada, the most important factors affecting their decisions are structured hours, lifestyle, financial considerations, interest in specific disease/patient population, and location. ${ }^{2}$ Surgical residents from the United States of America (USA) are most influenced by the potential of that specialty in their state. ${ }^{3}$ Factors such as acquisition of special skills, challenging diagnostic problems, role models and mentors are regarded by ophthalmology residents from the USA. ${ }^{4}$

There is a lack of data assessing factors that influence the career and subspecialty decisions of PRM residents in Turkey. Therefore, in this study, we aimed to determine the preferences of PRM residents in Turkey for future career choices, subspecialty training plans, and practice location and to identify the factors that influence those preferences.

\section{MATERIALS AND METHODS}

This survey study was designed by the Occupational Working Group of the Turkish
League Against Rheumatism (TLAR) and performed at Bezmialem Vakif University between January 2017 and July 2017. An electronic 23-question survey generated through Google Forms was mailed to 500 PRM residents (postgraduate years one-four) enrolled in the Turkish Society of Physical Medicine and Rehabilitation and the TLAR. The e-mail contained information about the study objectives and a link to the online electronic survey. E-mails were sent weekly to remind PRM residents to fill out the survey between April and July 2017. A total of 181 residents (36\%) (74 males, 107 females; mean age 28.8 years; range 24 to 40 years) responded to the survey. The study protocol was approved by the Bezmialem Vakif University Ethics Committee. The study was conducted in accordance with the principles of the Declaration of Helsinki.

The survey consisted of nine sections: (i) demographic information such as age, sex, marital status, training institution, postgraduate year; (ii) presence of subspecialty divisions; (iii) self-assessment of rheumatology training, knowledge and injection skills; (iv) preferences for future practice location after residency; $(v)$ desire to pursue fellowship training, type of fellowship, and influential factors; (vi) factors influencing the location choice for fellowship training and preferences for practice location after fellowship training; (vii) factors that cause residents to be indecisive about pursuing fellowship training;

\begin{tabular}{|lccc|}
\hline \multicolumn{2}{|c|}{ Table 1. Demographic information of respondents ( $\mathrm{n}=181$ ) } & \\
\hline Variables & $\mathrm{n}$ & $\%$ & Mean \pm SD \\
\hline Age (year) & & & $28.8 \pm 2.6$ \\
Sex & & & \\
Male & 74 & 40.9 & \\
Female & 107 & 59.1 & \\
Marital status & & & \\
Married & 109 & 60.2 & \\
Single & 72 & 39.8 & \\
Postgraduate year & & & \\
PGY-1 & 28 & 15.5 & \\
PGY-2 & 25 & 13.8 & \\
PGY-3 & 29 & 16.0 & \\
PGY-4 & 99 & 54.7 & \\
Current teaching hospital & & & \\
State University & 107 & 59.1 & \\
Foundation University & 13 & 7.2 & \\
$\quad$ Training and Research Hospital & 61 & 33.7 & \\
\hline SD: Standard deviation; PGY: Postgraduate year. & & & \\
\end{tabular}


Table 2. Demographic profile of physical and rehabilitation medicine clinics

\begin{tabular}{lc}
\hline & $\mathrm{n}$ \\
\hline Is there a division of rheumatology in your physical and rehabilitation medicine department? & 78 \\
Yes & 43.1 \\
No & 56.9 \\
Is there a division of algology in your physical and rehabilitation medicine department? & 403 \\
Yes & 25.4 \\
No & 74.6 \\
Is there an outpatient clinic for rheumatology patients in your physical and rehabilitation medicine department? & 138 \\
Yes & 76.2 \\
No & 43 \\
Is there an inpatient clinic for rheumatology patients in your physical and rehabilitation medicine department? & 23.8 \\
Yes & 136 \\
No & 75.1 \\
Does the presence of rheumatology or algology division in your physical and rehabilitation medicine department affect & 45 \\
your decision regarding fellowship training? & 24.9 \\
Yes & \\
No & 95 \\
\end{tabular}

(viii) factors that cause residents to be reluctant about pursuing fellowship training; and finally (ix), which was optional, opinions and suggestions about the survey. Survey questions were based on a survey that was conducted among specialists of PRM by Sendur et al.,$^{5}$ and studies about career and subspecialty training choices across all other disciplines. The survey was approved by consensus with the Occupational Working Group of the TLAR. The TLAR is the

Table 3. Survey responses regarding self-assessment of rheumatology training and injection skills

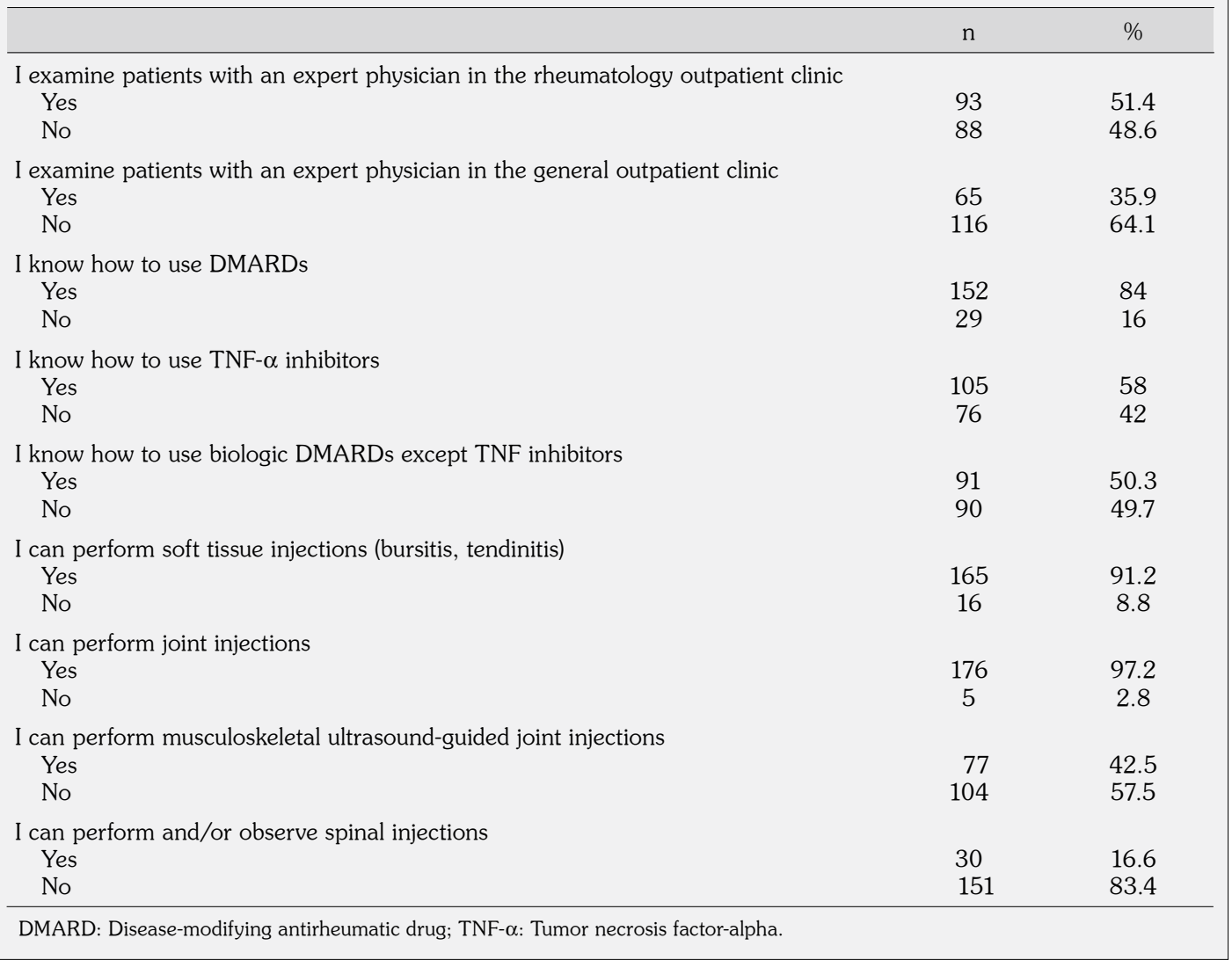




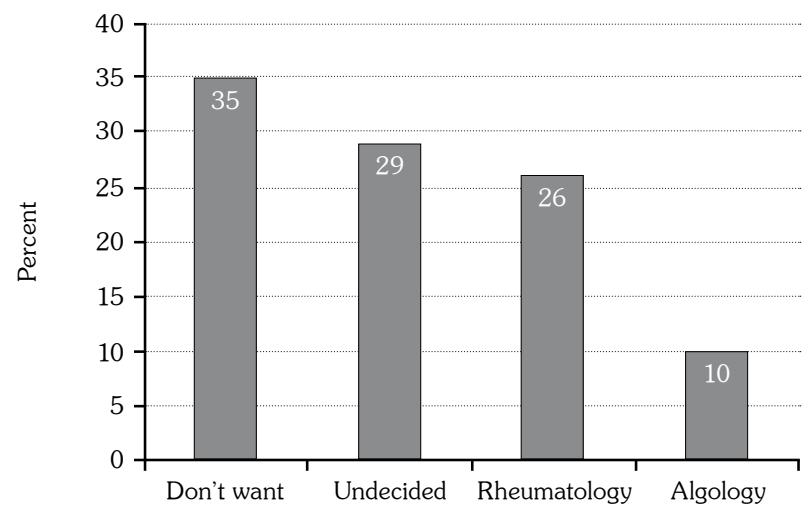

Figure 1. Percentage of physical and rehabilitation medicine residents planning to pursue a fellowship training.

first rheumatology association in Turkey. It was established in the same year as the European League Against Rheumatism (EULAR) in 1947 in order to reduce the burden of rheumatic diseases on individuals and society, and to encourage, improve, and support training and research on treatment, prevention of diseases, and the rehabilitation of musculoskeletal

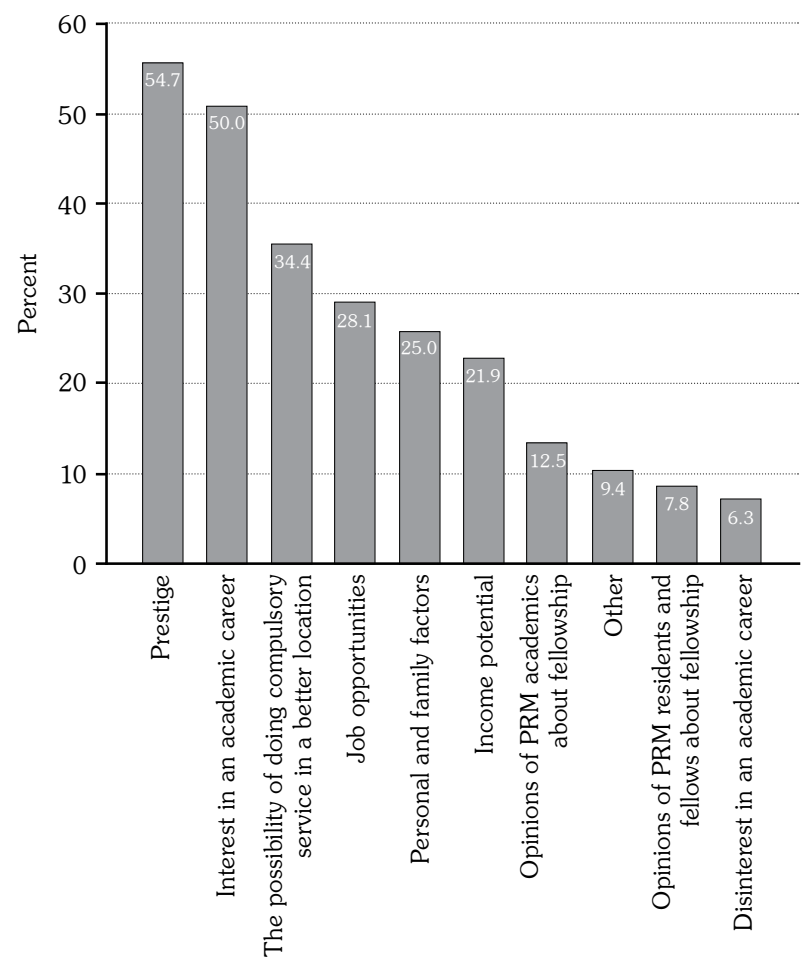

Figure 2. Influential factors for residents planning to pursue fellowship training. PRM: Physical and rehabilitation medicine. diseases. ${ }^{1}$ The link to this survey is as follows: https://goo.gl/forms/qNOmLhiifQVwdXA72.

\section{Statistical analysis}

Mean, percentage distribution, and standard deviation values were calculated using descriptive statistical methods. For categorical variables, the Chi-square test was performed. A p value of 0.05 or less was considered statistically significant and IBM-SPSS version 23.0 (IBM Corp., Armonk, NY, USA) was used for all statistical analyses.

\section{RESULTS}

A total of 181 (36\% response rate) PRM residents responded to the online survey. Of the 181 respondents, 109 (60.2\%) were married, and 72 (39.8\%) were single. The highest response rate was from postgraduate year four (54.7\%). Almost $60 \%$ (59.1\%) of the respondents were from state universities (Table 1). Seventyeight respondents (43.1\%) had a division of rheumatology and 46 (25.4\%) had a division

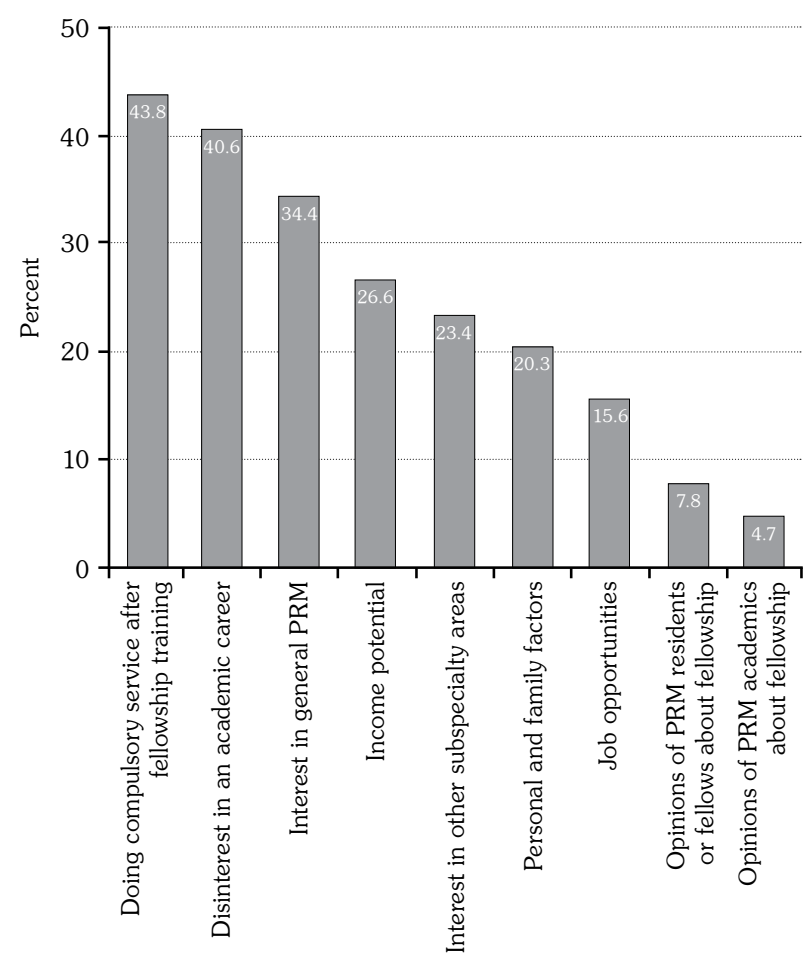

Figure 3. Influential factors for residents who do not want to pursue fellowship training. PRM: Physical and rehabilitation medicine. 
of algology in their PRM departments; 76.2\% had outpatient clinics and $75.1 \%$ had inpatient clinics for rheumatology patients. The presence of rheumatology or algology divisions in the PRM departments affected $52.5 \%$ of the respondents' decisions regarding fellowship training (Table 2). There was no statistically significant difference in the decision as to whether the respondents desired to pursue subspecialty training based on age, marital status, postgraduate year, training institution, or examination of rheumatology patients in an out/inpatient clinic (Chi-square [ $\left.\chi^{2}\right]$, $\mathrm{p}>0.05$ ). In the examination of sex differences in the choice of fellowships, male residents were found to be significantly more likely than female residents to plan on pursuing fellowship training (48.6\% vs. $\left.26.2 \% ; \chi^{2}, p<0.05\right)$.

Ninety-three (51.4\%) residents examined patients with an expert physician in rheumatology outpatient clinics, 152 (84\%) knew how to use diseasemodifying antirheumatic drugs (DMARDs), 105 (58\%) knew how to use tumor necrosis factor-alpha inhibitors, and 91 (50.3\%) knew how to use biologic DMARDs except tumor necrosis factor inhibitors. One-hundred and sixty-five respondents (91.2\%)

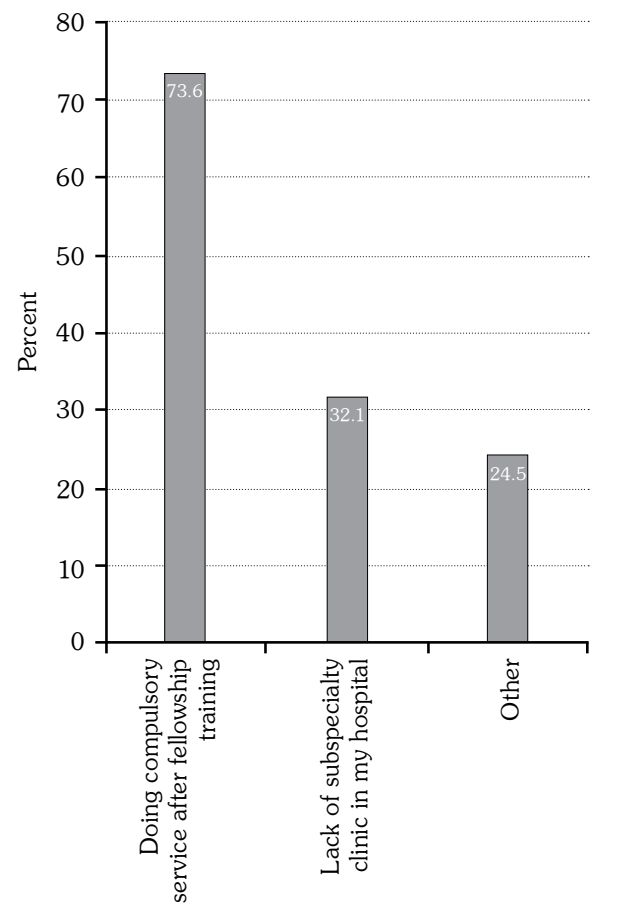

Figure 4. Reasons for being undecided about fellowship training. could perform soft tissue injections and 176 (97.2\%) were able to administer joint injections, but only $77(42.5 \%)$ reported being able to perform musculoskeletal ultrasound-guided injections. Only 30 respondents (16.6\%) could perform and/or observe spinal injections (Table 3). Respondents ranked their rheumatology education to date from one to ten and the mean value was $4.94 \pm 2.285$. There was no statistically significant difference in the decision whether to pursue subspecialty training based on the personal experiences of the respondents $\left(\chi^{2}, p<0.05\right)$.

Twenty-six percent of the respondents indicated that they planned to pursue a rheumatology fellowship, whereas $9.4 \%$ wanted to take an algology fellowship; $35.4 \%$ responded negatively and 29.3\% were undecided regarding fellowship (Figure 1). Having an algology division in the PRM department was positively associated with planning to pursue algology fellowship training $\left(\chi^{2}, p<0.05\right)$.

Among the residents who planned to receive fellowship training, prestige (54.7\%), being interested in an academic career (50\%), and the possibility of performing compulsory service in

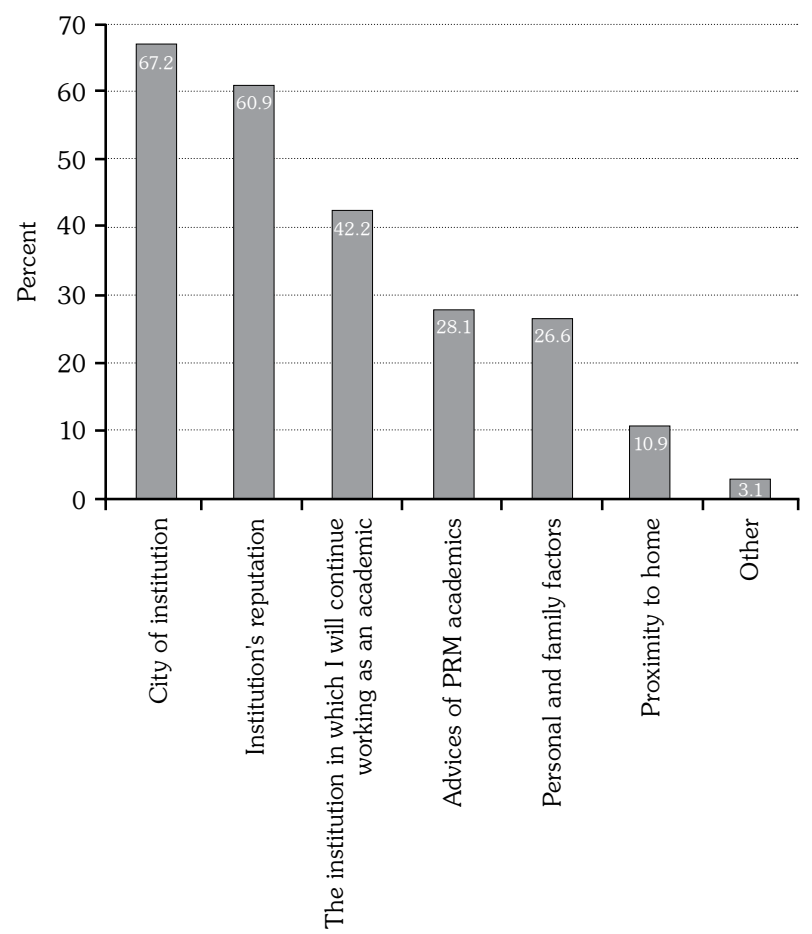

Figure 5. Factors influencing residents' fellowship training practice location preferences. PRM: Physical and rehabilitation medicine. 


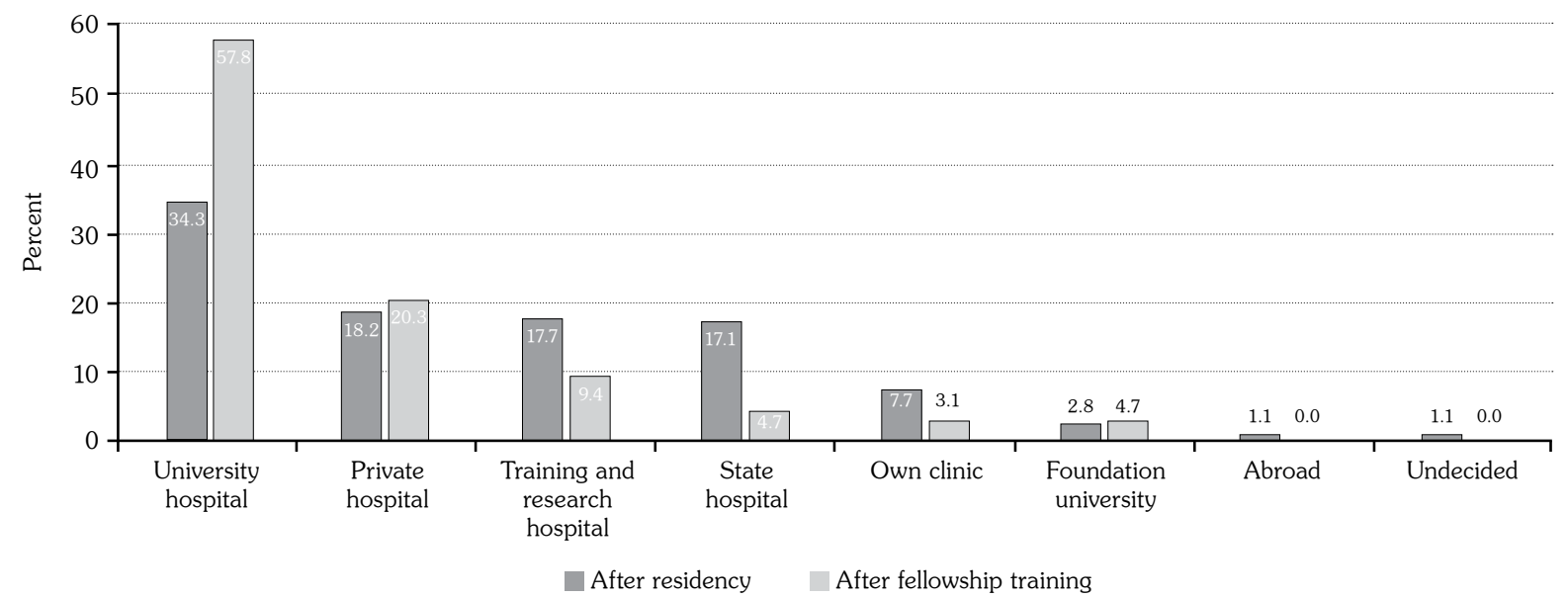

Figure 6. Preferences of future practice location after residency and fellowship training.

a better location (34.4\%) were the most common factors influencing this decision (Figure 2).

Of the $35.4 \%$ of residents who did not plan on pursuing fellowship training, $43.8 \%$ responded that performing compulsory service was influential in their decision. Other motivating factors reported by these residents included being disinterested in an academic career (40.6\%), being interested in general PRM (34.4\%), income potential (26.6\%), being interested in other specific areas (23.4\%) (e.g., pediatric rehabilitation, spinal cord injury medicine, brain injury medicine, electrodiagnostic medicine), personal and family factors (20.3\%), job opportunities (15.6\%), opinions of PRM residents or fellows (7.8\%), and opinions of PRM academics about fellowship training (4.7\%) (Figure 3).

Of the $29.3 \%$ of residents who were undecided about taking a fellowship, majority (73.6\%) said that performing compulsory service after fellowship training was definitely important. The second most important factor was the lack of subspecialty clinics in training hospitals (32.1\%) while other answers (24.5\%) were low income, the thought of going on residency training, lack of equipment in algology clinics, not being allowed to work as a specialist of PRM with the public after subspecialty training, working in a more specific content area, and problems in fellowship training (Figure 4).

Considering the location of fellowship training, the most influential factors were the city of the institution (67.2\%), the institution's reputation (60.9\%), and the intention to continue working in the same institution as an academic after fellowship training (42.2\%) (Figure 5).

When asked where they intended to practice, $34.3 \%$ of the respondents indicated that they desired to work in university hospitals after residency; 57.8\% who planned to pursue fellowship training preferred to practice at university hospitals after their fellowship and $42.2 \%$ who planned to pursue fellowship training intended to continue working at the same institution upon completion of their training (Figure 5). Private hospitals were the second preferred practice location and training and research hospitals were the third (Figure 6). Thus, an academically oriented career was the most desirable career choice.

\section{DISCUSSION}

This study investigated the preferences and influential factors of PRM residents training in Turkey while making their career and subspecialty training plans. To our knowledge, this is the first study to provide a snapshot of Turkish PRM residents at all levels of training with a $36 \%$ response rate. Our results indicate that $35.4 \%$ of PRM residents plan to pursue fellowship training. Many disciplines have a high fellowship interest, for example, it is $70 \%$ for anesthesiology in Canada, and 69\% for urology, 55\% for general surgery, and $64 \%$ for ophthalmology in the USA. ${ }^{3,4,6,7}$ Our result corresponded to nearly half of these percentages, which may be due to the high percentage of undecided residents (29.3\%). 
In our study, male sex was associated with a desire to pursue fellowship training. Similarly, other studies have also shown that males were more likely to pursue subspecialty training, including anesthesiology, pediatrics, and ophthalmology residents. ${ }^{4,6,8}$ Greater responsibilities (domestic and childcare) and susceptibility to burnout caused females' reluctance to pursue fellowship training. ${ }^{9-11}$ Although many factors can contribute to career and subspecialty decision-making, we determined the most influential factors that shaped both processes.

The perceived higher prestige was the most efficient and motivating factor for respondents who planned to pursue fellowship training. Being fellowship-trained is attractive and has a competitive advantage in hiring processes at institutions. ${ }^{12,13}$

Studies in ophthalmology, neurosurgery, and urology disciplines showed that there is a belief that holding a subspecialty certification brought

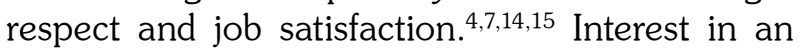
academic career (university versus non-university practice type) was the second most common factor for those desiring to pursue fellowship training. Some 57.8\% of residents desired to practice at university hospitals after fellowship training.

Fellowship-trained physicians easily focus their field of interest and have new research opportunities in an academic setting. University hospitals can provide varied research sources and encourage participating in research projects. They can also provide greater satisfaction in financial needs. Our results were similar to those of studies in fields of ophthalmology, neurosurgery, anesthesiology, radiology, and urology. 4,6,7,13,16

Performing compulsory service was the uppermost factor for those who were unsure and those who did not want to pursue fellowship training. The Turkish Society of Medical Oncology declared that compulsory service caused family disruptions and an unwillingness to pursue a subspecialty. Compulsory service has been suggested to be undertaken only once after specialty training in order to motivate residents to pursue subspecialty training.

Furthermore, income potential influences career planning and the decision to pursue fellowship training. ${ }^{17}$ In Turkey, fellows receive almost the same salary as residents, and this may motivate residents negatively for prolonged training. Similarly, in our survey, pursuing subspecialty training was associated with low income by residents who were undecided about receiving fellowship training.

There are two fellowship training programs as rheumatology and algology in Turkey. The rheumatology fellowship involves a three-year while the algology fellowship involves a twoyear clinical training. In our survey, the most popular PRM subspecialty was rheumatology. The availability of new drugs such as biologics definitely renders rheumatology more appealing. Rheumatology has a controllable lifestyle appeal for younger doctors seeking a work-life balance. ${ }^{18}$ Other desired fellowship programs were pediatric rehabilitation, neurorehabilitation and spasticity, brain injury medicine, spinal cord injury, cardiac rehabilitation, geriatric rehabilitation, and clinical neurophysiology.

In Turkey, basic standards for the teaching staff and educational resource materials for education of the fellows are established by the Board for Medical Specialties. The number of academicians and teaching staff, educational resource materials and research activity may be the factors that define the quality of the training program of a subspecialty.

The decision of the location of future practice also provides an insight into significant considerations in resident career planning. Most residents interested in subspecialty training prioritized the city of the institution and institution reputation while deciding in the location of fellowship practice. They also preferred to continue working at the same institution upon completion of fellowship training. This finding suggests that the career plans of PRM residents in Turkey are not based solely on personal and professional desires, but require consideration of compulsory service.

There are two limitations in this study. First, the survey response rate (36\%) may not be entirely representative of all PRM residents in Turkey. Second, our results cannot be generalized to countries where compulsory service is not enforced. 
In conclusion, understanding the career preferences of residents may assist in shaping residency program planning and future strategies of the Ministry of Health. Nevertheless, the preferences of PRM residents and influential factors may change as new subspecialties emerge and with reforms in the compulsory service. We hope that this study will serve as a framework to document the career and subspecialty preferences and motivations of PRM residents training in Turkey.

\section{Declaration of conflicting interests}

The authors declared no conflicts of interest with respect to the authorship and/or publication of this article.

\section{Funding}

The authors received no financial support for the research and/or authorship of this article.

\section{REFERENCES}

1. Bodur H. The Fight against rheumatism is in its 70th year. Arch Rheumatol 2017;32:1-2.

2. Freed GL, Dunham KM, Jones MD Jr, McGuinness GA, Althouse L. General pediatrics resident perspectives on training decisions and career choice. Pediatrics 2009;123:26-30.

3. Incorvaia AN, Ringley CD, Boysen DA. Factors influencing surgical career decisions. Curr Surg 2005;62:429-35.

4. Gedde SJ, Budenz DL, Haft P, Tielsch JM, Lee Y, Quigley HA. Factors influencing career choices among graduating ophthalmology residents. Ophthalmology 2005;112:1247-54.

5. Sendur OF, Kuran B, Dogan D, Alptekin JO, Birtane $\mathrm{M}$, Bodur $\mathrm{H}$ ve ark. FTR uzman hekimlerinin romatolojiye yaklaşımı anketi sonuçları-(3): Klinik uygulamalar ve bilimsel çalışmalar. 8. Uluslararası Katılımlı Türk Romatoloji Kongresi, 22-26 Mart 2017, Antalya, Türkiye; 2017.
6. Khan J, Gilbert J, Sharma A, LeManach Y, Yee D. Perspectives of anesthesia residents training in Canada on fellowship training, research, and future practice location. Can J Anaesth 2015;62:956-63.

7. Freilich DA, Nguyen HT, Phillips JL. Factors influencing residents' pursuit of urology fellowships. Urology 2011;78:986-92.

8. Pan RJ, Cull WL, Brotherton SE. Pediatric residents' career intentions: data from the leading edge of the pediatrician workforce. Pediatrics 2002;109:182-8.

9. Gautam M. Women in medicine: stresses and solutions. West J Med 2001;174:37-41.

10. Borman KR, Biester TW, Rhodes RS. Motivations to pursue fellowships are gender neutral. Arch Surg 2010;145:671-8.

11. McMurray JE, Linzer M, Konrad TR, Douglas J, Shugerman R, Nelson K. The work lives of women physicians results from the physician work life study. The SGIM Career Satisfaction Study Group. J Gen Intern Med 2000;15:372-80.

12. Ryan MW, Johnson F. Fellowship training in otolaryngology-head and neck surgery. Otolaryngol Clin North Am 2007;40:1311-22.

13. Hurley RW, Zhao K, Tighe PJ, Ko PS, Pronovost PJ, $\mathrm{Wu}$ CL. Examination of publications from academic anesthesiology faculty in the United States. Anesth Analg 2014;118:192-9.

14. Lee TT, Klose JL. Survey on neurosurgery subspecialty fellowship training. Congress of Neurological Surgeons Education Committee. Surg Neurol 1999;52:641-4.

15. Moshe M, Perry ZH, Salzer L, Zemora E, Toker A. Work satisfaction, quality of life, and leisure time of neonatology fellows and senior neonatologists in Israel. Isr J Health Policy Res 2012;1:50.

16. Mok PS, Probyn L, Finlay K. Factors Influencing Radiology Residents' Fellowship Training and Practice Preferences in Canada. Can Assoc Radiol J 2016;67:99-104.

17. Garibaldi RA, Popkave C, Bylsma W. Career plans for trainees in internal medicine residency programs. Acad Med 2005;80:507-12.

18. Kolasinski SL, Bass AR, Kane-Wanger GF, Libman BS, Sandorfi N, Utset T. Subspecialty choice: why did you become a rheumatologist? Arthritis Rheum 2007;57:1546-51. 